\title{
誘導結合高周波プラズマ支援マグネトロンスパッタを 用いた極薄アルミナ膜の作製*
}

\author{
森田 正 ${ }^{* 1} \cdot$ 山本 直志 ${ }^{* 1} \cdot$ 倉内 利春*1 ${ }^{*}$ 松浦 正道*1
}

（受理1997年11月28日，掲載決定1998年 2 月 7 日）

Preparation of Very Thin $\mathrm{Al}_{2} \mathrm{O}_{3}$ Films by Magnetron Sputtering Enhanced with an Inductively Coupled rf Plasma

Tadashi MORITA, Tadashi YAMAMOTO, Toshiharu KURAUCHI and Masamichi MATSUURA

(Tsukuba Insitute for Super Materials, ULVAC JAPAN Ltd., 29 Wadai, Tsukuba, Ibaraki, 300-4247)

(Received November 28, 1997, Accepted February 7, 1998)

Very thin $\mathrm{Al}_{2} \mathrm{O}_{3}$ film is required for insulation gap layers in future magnetic recording storage devices. In this study, very thin $\mathrm{Al}_{2} \mathrm{O}_{3}$ films of various thicknesses were prepared by means of a newly developed magnetron sputtering system based on a process that we have termed "magnetron sputtering enhanced with an inductively coupled rf plasma." The cathode in this system has an rf coil attached to the planer magnetron sputtering target. The breakdown voltages of the $\mathrm{Al}_{2} \mathrm{O}_{3}$ films were about $5 \mathrm{MV} / \mathrm{cm}$ and leakage currents were $\leqq 10^{-7} \mathrm{~A} / \mathrm{mm}^{2}$. The surface roughness of the film was controllable by varying the input power to the rf coil, which also affected its breakdown properties. The Rmax for several of the film surfaces was $\leqq 1 \mathrm{~nm}$.

\section{1. はじめに}

次世代ハードディスクの高記録密度化を進める技術と して, 磁性媒体の高保磁力化と磁気へッドとしてスピン バルブ (SV), 巨大磁気抵抗 (GMR) ヘッドの実用化 が期待されている1). これらの磁気へッド作製には極薄 の人工格子磁性膜に加えギャップ層を形成するため極め て薄く平滑な絶縁性薄膜が不可欠である. 他方, 我々は,

Fig. 1 に示す新しいタイプのスパッタリングカソード （誘導結合高周波プラズマ支援マグネトロンスパッタカ ソード）を開発している．このカソードは，平行平板型 マグネトロンカソードの上に高周波コイルを取り付けた 構造になっている.このコイルによる誘導結合高周波プ ラズマの働きにより従来スパッタ法に比ベスパッタ粒子 のイオン化率を高くすると共にそのイオンエネギーを制 御しながらの成膜が可能になる ${ }^{2,3)}$ 。これまで我々は本

\footnotetext{
$*$ 平成 9 年 11 月 6 日 第 38 回真空に関する連合講演会で講演 $(6 \mathrm{Ap}-6)$
}

*1 日本真空技術媒筑波超材料研究所（开300-42 茨城県つくば市和台29）

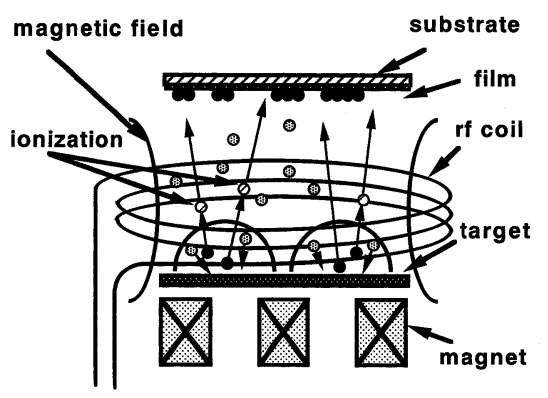

Fig. 1 Schematic diagram of the magnetron sputtering source enhanced with an inductively coupled rf plasma.

スパッタ法を用いることにより化合物膜の結晶配向性制 御が可能である事や結晶性の良好な成膜がでさる事，ま た，低圧放電，遠隔スパッタ構成により基板の昇温や膜 へのプラズマダメージが少ないことを示してきた ${ }^{2-5)}$ れらの理由から本研究では, 次世代 HDDへッドのギャ ップ形成用絶縁膜に要求される極薄膜 $(30 \sim 50 \mathrm{~nm})$ で 
Table 1 Experimental coditions for $\mathrm{Al}_{2} \mathrm{O}_{3}$ films prepared by magnetron sputtering enhanced with an inductively coupled rf plasma

\begin{tabular}{|c|c|c|}
\hline & rf sputtering & $\begin{array}{l}\text { DC reactive } \\
\text { sputtering }\end{array}$ \\
\hline Target & $\mathrm{Al}_{2} \mathrm{O}_{3}$ & $\mathrm{Al}$ \\
\hline Total pressure & $0.1 \mathrm{~Pa}$ & $0.1 \mathrm{~Pa}$ \\
\hline $\mathrm{O}_{2}$ partial pressure & - & $\begin{array}{l}5 \times 10^{-3} \mathrm{~Pa} \sim \\
9 \times 10^{-3} \mathrm{~Pa}\end{array}$ \\
\hline Cathode power & rf $150 \mathrm{~W}$ & $\begin{array}{l}\text { DG } 150 \mathrm{~W} \\
(0.35 \mathrm{~A} \times 430 \mathrm{~V})\end{array}$ \\
\hline rf coil power & $25 \mathrm{~W} \sim 100 \mathrm{~W}$ & $20 \mathrm{~W} \sim 50 \mathrm{~W}$ \\
\hline $\begin{array}{l}\text { Substrate } \\
\text { temperature }\end{array}$ & R.T. & R.T. \\
\hline $\begin{array}{l}\text { Tarhet/substrate } \\
\text { distance }\end{array}$ & $200 \mathrm{~m}$ & $200 \mathrm{~m}$ \\
\hline Deposition rate & $1.7 \times 10^{-2} \mathrm{~nm} / \mathrm{s}$ & $0.17 \mathrm{~nm} / \mathrm{s}$ \\
\hline
\end{tabular}

高絶縁耐圧・低リーク電流特性が必要な $\mathrm{Al}_{2} \mathrm{O}_{3}$ 膜を作製 し，その電気特性を評価した. $\mathrm{Al}_{2} \mathrm{O}_{3}$ 膜堆積法として は, ターゲットに $\mathrm{Al}_{2} \mathrm{O}_{3}$ を用いる高周波スパッタ法と $\mathrm{Al}$ を用いる反応性スパッタ法の 2 種類を試みた.

\section{2. 実験方法}

Fig. 2 に本成膜装置の概要を示す. 本装置は 8 " クラ イオポンプにより排気されている. 本カソードの誘導結 合放電用高周波コイル ( $\phi 5$ 水冷 $\mathrm{Cu}$ パイプ, コイル径 $\phi 76,3$ ターン) はターゲット上に設置されている. コイ ル電極終端は，プラズマ電位を制御する LCR 回路を経 由してアースに接続されている.コイルには，周波数 $13.56 \mathrm{MHz}$ の高周波電源を接続した。ターゲット形状 は, $\phi 2$ "で厚さが $5 \mathrm{~mm}$ である.ターゲット材料は $\mathrm{Al}_{2} \mathrm{O}_{3}$ (99.9\%) と $\mathrm{Al}$ (99.999\%) を用いた。スパッタ電源に は $\mathrm{Al}_{2} \mathrm{O}_{3}$ ターゲットの場合は高周波電源（13.56 MHz）， $\mathrm{Al}$ ターゲットの場合は直流電源を用いた。ささらに直流 電源には，アーク放電防止回路を付加することで反応性 スパッタに拈いて問題となる放電の不安定化を抑制し た.スパッタガスである Arはカソード上のノズルより 導入し, 反応ガスである酸素は雾囲気導入とした. $\mathrm{Al}_{2}$ $\mathrm{O}_{3}$ ターゲットを用いた場合には酸素ガスは導入しなか

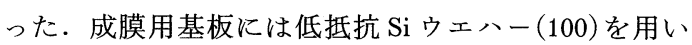
た. 基板はフローティングとした. 成膜条件としてはカ ソード電力を $150 \mathrm{~W}$ 一定, 高周波コイルヘの電力を可 変とした。 また，成膜中の全圧 $0.1 \mathrm{~Pa}$ 一定とした。基板 ターゲット間距離は200 $\mathrm{mm}$, 成膜中の基板温度は室温 とした. 以上の状態で高周波コイルへ投入する電力を変 化させることにより作製した $\mathrm{Al}_{2} \mathrm{O}_{3}$ 膜の $\mathrm{V}-\mathrm{I}$ 特性変化 を調べた，V-I 特性を測定するために用いた $\mathrm{Cu}$ 電極

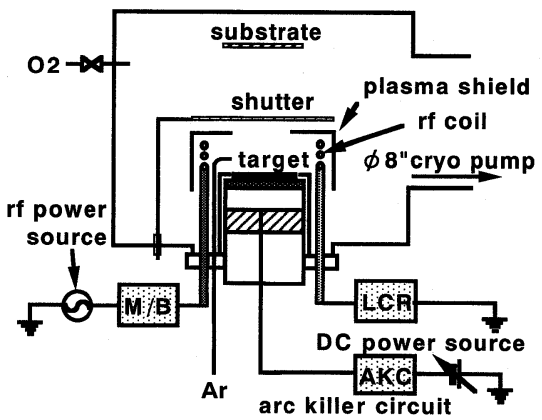

Fig. 2 Schematic diagram of the magnetron sputtering system enhanced with an inductively coupled rf plasma.

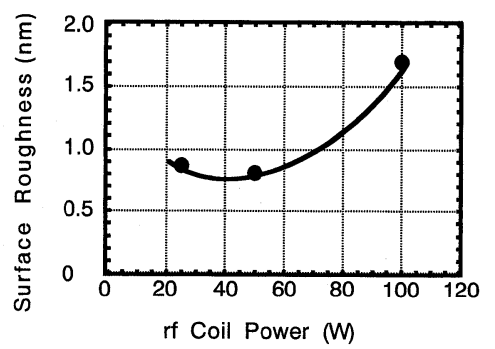

Fig. 3 Relation between $\mathrm{rf}$ coil power and surface roughness of the $\mathrm{Al}_{2} \mathrm{O}_{3}$ films prepared by rf sputtering. $\left(\mathrm{Al}_{2} \mathrm{O}_{3}\right.$ target $)$

$(500 \mu \mathrm{m} \times 500 \mu \mathrm{m})$ はスパッタ法により作製した．膜表 面の粗さは AFM (Atomic Force Microscop: DI 社製/ nanoscoop-D3000）を用て測定した.

\section{3. 実験結果}

\section{3. $1 \mathrm{Al}_{2} \mathrm{O}_{3}$ ターゲットからの成膜}

高周波コイルに投入する電力をパラメーターにして厚 さ50 nm の $\mathrm{Al}_{2} \mathrm{O}_{3}$ 膜を作製した。作製した膜の表面粗さ を $\mathrm{AFM}$ を用いて測定した結果を Fig. 3 亿示す． $R_{\max }$ が $1 \mathrm{~nm}$ の Si ウェハー上に成膜した場合に执いて高周波 ユイル投入電力が $25,50 \mathrm{~W}$ で成膜した試料では表面粗 さは0.8 0.9 nm であり基板より平坦な膜が得られてい る. 成膜前後での基板表面粗さ変化を Fig. 4 の AFM 像で示す．明らかに基板表面の凸凹が小さくなっている ことがわかる. 一方，コイル投入電力が $100 \mathrm{~W}$ のでは膜 表面の荒れが大きくなった。この試料について耐圧試験 を行ったところ，ほとんどの測定点で絶縁性が得られな かった．膜表面の平坦性が良好な条件で作製した膜の V 一 I 特性を Fig. 5 に示す. 絶縁耐圧は約 $5 \mathrm{MV} / \mathrm{cm}$, リ ーク電流值は $10^{-7} \mathrm{~A} / \mathrm{mm}^{2}(10 \mathrm{~V})$ を有していた. $\mathrm{Al}_{2} \mathrm{O}_{3}$ ターゲットから高周波スパッタにて作製した $\mathrm{Al}_{2} \mathrm{O}_{3}$ 膜の 屈折率をエリプソメーターを用いて測定したところ 1.64 


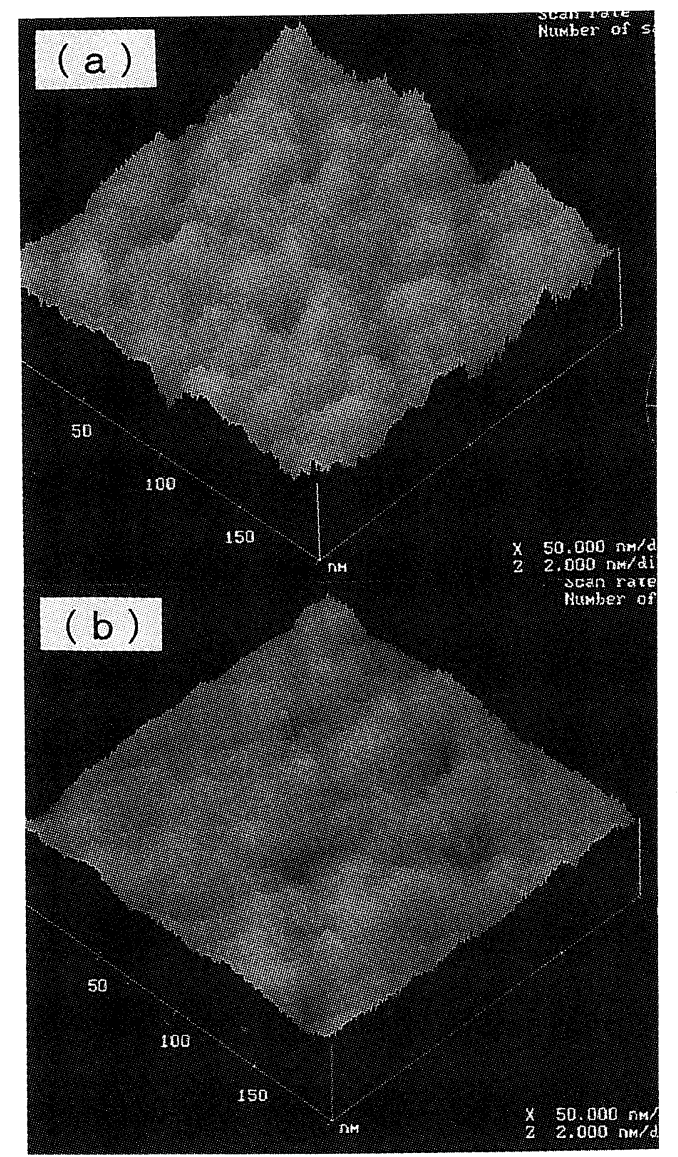

Fig. 4 AFM images (a) The Si substrate surface before deposition, (b) The sample surface after $\mathrm{Al}_{2} \mathrm{O}_{3}$ films deposition.

であった。また，成膜速度は $1.7 \times 10^{-2} \mathrm{~nm} / \mathrm{sec}$ 程度であ った.

\section{$3.2 \mathrm{Al}$ ターゲットからの成膜}

$\mathrm{Al}$ ターゲットを使用した本実験に拈いては高周波コ イルに投入する電力と反応ガスである酸素分圧をパラメ ーターにして $\mathrm{Al}_{2} \mathrm{O}_{3}$ 膜を作製した。（膜厚 $30 \mathrm{~nm}$ ）酸素 分圧を決めるにあたり予備テストを行い, 膜の屈折率が ほぼ，バルクと同等な值 $(n=1.7)$ の条件を見い出し た.また，このとき作製した膜のオージェ電子分光分析 を行い, $\mathrm{Al}$ オージェスペクトルのピークエネルギー值 及びスペクトル形状より膜中に未反応 $\mathrm{Al}$ が存在しない ことを確認した。この時の酸素分圧值 $5 \times 10^{-3} \mathrm{~Pa}$ を酸 素分圧の最少值とした．AFMによる膜の表面粗さ測定 結果を Fig. 6 に示す。また AFM 像による膜表面粗さ の違いを Fig. 7 に示す.わずかではあるが高周波コイ ル電力が大きくなることで膜表面の粗れが大きくなって いる. $R_{\max }$ が $1 \mathrm{~nm}$ である $\mathrm{Si}$ ウェハー上に成膜した場

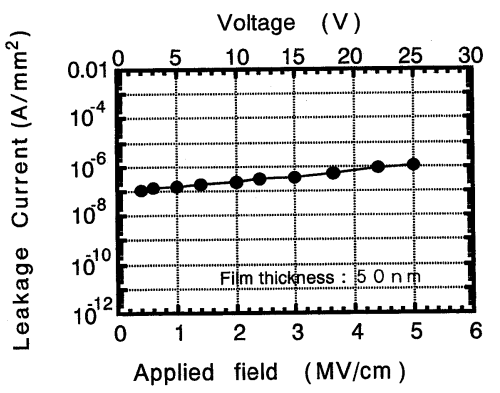

Fig. $5 \mathrm{~V}-\mathrm{I}$ characteristics of an $\mathrm{Al}_{2} \mathrm{O}_{3}$ films prepared by $\mathrm{rf}$ sputtering. $\left(\mathrm{Al}_{2} \mathrm{O}_{3}\right.$ tir get)

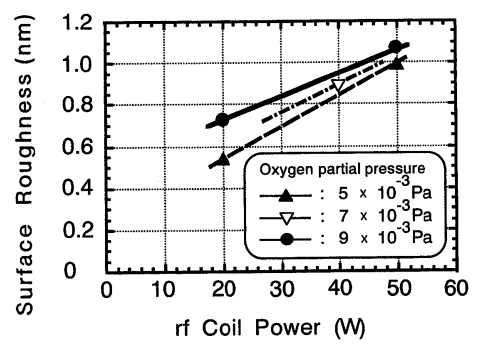

Fig. 6 Relation between rf coil power and surface roughness of the $\mathrm{Al}_{2} \mathrm{O}_{3}$ films prepared by $\mathrm{DC}$ reactive sputtering. (Al target)

合に扣いて高周波コイル投入電力を大きくすること，酸 素分圧が増加することで膜表面の粗れが大きくなってい る.コイル電力を $100 \mathrm{~W}$ まで大きくした場合は基板ホル ダー周囲に拈ける異常放電により成膜状態が不安定にな ったため試料を作製することがでさなかった．50 W 以 下のコイル電力で成膜した試料では表面粗さは $0.8 \sim 0.9$ $\mathrm{nm}$ 以下であり基板より平坦な膜が得られている。 これ らの試料について耐圧試験を行い成膜条件による絶縁破 壊電圧の変化を調べた結果を Fig. 8 に示す. 絶縁耐圧

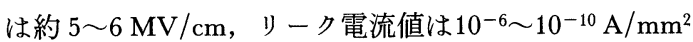
であった．高周波コイル電力 $20,50 \mathrm{~W}$ それぞれの場合 において酸素分圧により絶縁破壊電圧やリーク電流值が 変化している．高周波コイル電力が $20 \mathrm{~W}$ の場合, 酸素 分圧を $5 \times 10^{-3} \mathrm{~Pa}$ から $7 \times 10^{-3} \mathrm{~Pa}$ へ大きくする事で一 旦絶縁耐圧が上昇し， $9 \times 10^{-3} \mathrm{~Pa}$ まで大きくすると絶 縁耐圧がわずかに低下するもののリーク電流值が小さく なる傾向を示した. 次に $50 \mathrm{~W}$ の場合, 酸素分圧が $5 \times$ $10^{-3} \mathrm{~Pa}$ から $7 \times 10^{-3} \mathrm{~Pa}$ に扣いては絶縁耐圧とリーク電

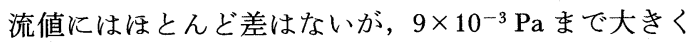
すると絶縁耐圧が小さくなる傾向があった. $\mathrm{Al}$ ターゲ ットから DC 反応性スパッタにて作製した $\mathrm{Al}_{2} \mathrm{O}_{3}$ 膜の屈 折率は1.70〜1.72であった。 また, 成膜速度は $0.17 \mathrm{~nm} /$ $\sec$ 程度であり $\mathrm{Al}_{2} \mathrm{O}_{3}$ ターゲットからの成膜した場合よ りも 1 桁速くなった。 


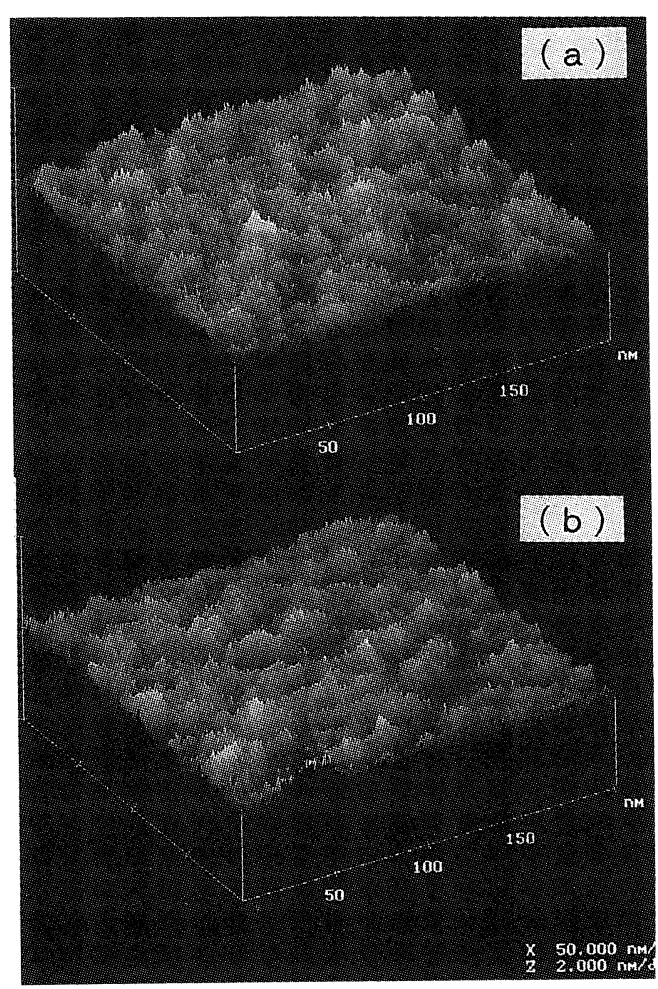

Fig. 7 AFM images of the sample surface after $\mathrm{Al}_{2} \mathrm{O}_{3}$ film deposition. The coil $\mathrm{rf}$ power were, (a) $20 \mathrm{~W}$, (b) $50 \mathrm{~W}$.

\section{4. 考察}

高周波コイルへの適度な高周波電力投入により膜表面 の平坦性が向上している事がわかった．また，この絶縁 膜リーク電流特性は小さくなっていた，これより本成膜 中に膜の平坦化と緻密化が同時に起きていると考光られ る.これは, 誘導結合放電により励起されたスパッタ粒 子による，ある種のバイアススパッタ作用による平坦化 とイオン衝撃による維密化の効果と考兄られる ${ }^{6)}$. 投入 する高周波電力が大き過ぎる場合，絶縁性の低下が起き ていた。これは, プラズマの電位が高くなり過ぎたこと によるスパッタ粒子や $\mathrm{Ar}$ イオンの基板表面へのダメー ジと考兄られる.このダメージにより膜表面が粗れるこ とで絶縁膜としての特性を低下させたと考兄られる.今 回は高周波スパッタ法と反応性スパッタ法を試みたが， それぞれの特長を比較すると、リーク電流值は反応性ス パッタ法で作製した膜の方が小さくなった。 また，絶縁 耐圧は $\mathrm{Al}_{2} \mathrm{O}_{3}$ ターゲットを使用した高周波スパッタに和 いてばらつきが大きいものの最大 $8 \mathrm{MV} / \mathrm{cm}$ の耐電圧を 有する場合もあった。 また，いら゙れの方法に㨟いても膜

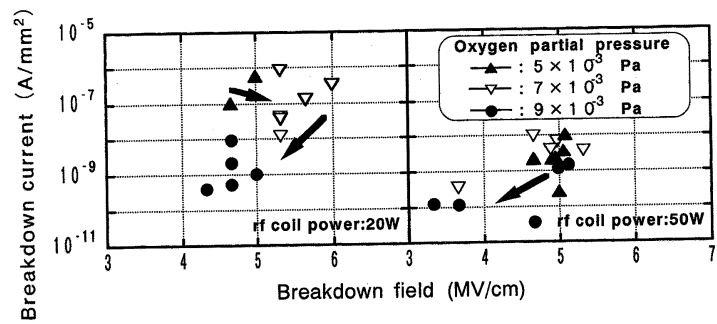

Fig. 8 Relation between breakdown field and breakdown current of the $\mathrm{Al}_{2} \mathrm{O}_{3}$ films prepared by $\mathrm{DC}$ reactive sputtering under various deposition parameters. (Al target)

表面の平坦性は基板表面のそれよりも良好であり, 高周 波コイルに投入する電力によって制御できることがわか った。

\section{5. 結 論}

誘導結合高周波プラズマ支援マグネトロンスパッタ法 により $\mathrm{Al}_{2} \mathrm{O}_{3}$ 膜の作製を行った結果，次の結論を得た。

1）AFMにより膜の表面粗さを測定した結果，元の 基板表面よりも平坦化されていることがわかった.

2) $\mathrm{Al}_{2} \mathrm{O}_{3}$ ターゲットから膜厚 $50 \mathrm{~nm}$ 成膜した場合の

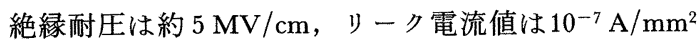
(10V) であった.

3） $\mathrm{Al}$ ターダットから反応性により作製した $\mathrm{Al}_{2} \mathrm{O}_{3}$ 膜は, 導入した酸素分圧と高周波コイル電力量により電 気特性が変化し，これらの条件を最適化する事で膜厚が $30 \mathrm{~nm}$ V抽いて, 絶緑破壊電圧が $5 \mathrm{MV} / \mathrm{cm}$ 以上ありり 一ク電流值が $10^{-8} \mathrm{~A} / \mathrm{mm}^{2}$ 以下の特性の膜を得ることが できた。

以上の結果より本スパッタ法で作製される $\mathrm{Al}_{2} \mathrm{O}_{3}$ 膜 は，高記録密度磁気記録へッドへの応用が期待できるこ とがわかった。

\section{〔文献〕}

1）三浦義正：日本応用磁気学会誌，20（1996） 879 .

2）松浦正道, 山本直志, 森田 正, 倉内利春 : 表面技 術協会第94回講演大会要旨集 (1996) p 226.

3) 山本直志, 森田 正, 倉内利春, 松浦正道 : 応用磁 気学会誌, 21 (1997) 569.

4) T. Yamamoto, T. Morita, T. Kurauchi, M. Hakomori, S. Misawa, T. Uchiyama and M. Matsuura: 13th IVC/9th ICSS, Yokohama, (1995) 250.

5）森田 正, 山本直志, 倉内利春, 三沢俊司, 松浦正 道 : 真空, 38 (1995) 255.

6）原田曠嗣：Semiconductor world, 10 (1984) 121. 